\title{
Melatih Kemandirian Anak Melalui Rutinitas Sehari-Hari
}

\author{
Rachel Risda Sitanggang ${ }^{1}$, Nuriyanti ${ }^{2}$ \\ Pendidikan Fisika, Fakultas Keguruan dan Ilmu Pendidikan, Universitas Jambi \\ rachelstg13@gmail.com
}

\begin{abstract}
ABSTRAK
Artikel ini merupakan penelitian yang bertujuan untuk memecahkan masalah yaitu meningkatkan kemandirian melalui kebiasaan atau rutinitas sehari-hari dari siswa-siswi kelas VII.1 dan VII.2 di SMP Nomennsen Kota Jambi. penelitian ini dilakkuan dengan cara deskriptif kuantitatif dan datanya diolah dengan metode statistika. Data yang diambil adalah 40 siswa dan dikumpulkan dengan angket atau kusioner. Hasil menunjukkan bahwa meningkatkan kemandirian melalui rutinitas atau kebiasaan sehari-hari merupakan cara praktis yang dapat dilakukan guru dan orang tua kepada anaknya, karena itu dapat membentuk kepribadian dan kemampuan anak menjadi lebih baik dan cepat. Kepribadian dan kemampuan anak yang baik akan berpengaruh terhadap mutu dan kualitas lulusan pendidikan di Indonesia, dimana kualitas yang baik adalah modal penting untuk dapat bersaing dengan lulusan dari negara lain.
\end{abstract}

Kata kunci: Kemandirian, Rutinitas, Kemandirian Anak

\section{ABSTRACT}

This article is a research that aims to solve the problem of increasing independence through daily habits or routines of students of class VII.1 and VII.2 in NOMENNSEN Middle School, Jambi City. this study was conducted in a quantitative descriptive way and the data was processed by statistical methods. The data taken was 40 students and collected by questionnaire or questionnaire. The results show that increasing independence through routine or daily habits is a practical way that teachers and parents can do to their children, because it can shape the personality and ability of children to be better and faster. Good children's personality and abilities will influence the quality and quality of education graduates in Indonesia, where good quality is an important capital to be able to compete with graduates from other countries.

Keywords: Independence, Routines, Independence of Children

\section{PENDAHULUAN}

Kualitas sumber daya manusia yang tinggi merupakan modal penting dalam pembengunan bangsa Indonesia untuk dapat bertahan ditengah zaman milenial ini. Pendidikan adalah salah satu cara bangsa Indonesia untuk meningkatkan kualitas sumber daya manusia. Hal ini karena besarnya pengaruh pendidikan terhadap kehidupan di masa sekarang ini dan pendidikan menjadi sarana penting dalam pengembangan sumber daya manusia. Sejauh mana kita memandang maka sejauh itulah kita harus melengkapi diri kita dengan pendidikan. Salah satu tujuan pendidikan adalah menyiapkan peserta didik menjadi anggota masyarakat yang memiliki kemampuan akademik atau professional yang dapat menerapkan dan mengembangkan ilmu pengetahuan (Aini dan Taman,2012). Pendidikan juga menuntut agar anggota masyarakatnya memiliki sikap yang baik dalam kehidupan berbangsa dan bernegara. Sehingga melalui pendidikan akan dapat dihasilkan sumber daya manusia yang berkualitas dan mampu bersaing.

Di Indonesia rumpun disiplin ilmu Ilmu pengetahuan alam (IPA) yang wajib dipelajari di sekolah dasar sampai menengah atas yaitu Fisika, Biologi, Kimia, dan juga IPBA. Rumpun disiplin ilmu IPA di SD dan SMP merupakan mata pelajaran terpadu sebagai IPA terpadu, berbeda dengan SMP yang menjadikan rumpun disiplin ilmu IPA sebagai mata pelajaran terpisah. Hal ini tertuang pada Permendikbud No. 58 Tahun 2014 tentang pembelajaran IPA di SMP dalam 
kurikulum 2013 hakikatnya sebagai mata pelajaran dalam bentuk integrated science dengan muatan IPA berasal dari disiplin Biologi, Fisika, Kimia dan IPBA. Materi Fisika, Kimia, Biologi dan IPBA dipadukan dengan harapan siswa mampu mengembangkan pengetahuan konsep dasar IPA secara utuh, sehingga ketika menemui suatu masalah IPA siswa dapat mengidentifi kasinya (Pratiwi \& Muslim,2016).

Siswa hruslah menjadi pusat saat proses pembelajaran, dengan memperhatikan perkembangan kognitif siswa tersebut. Kognitif merupakan salah satu aspek penting dari perkembangan peserta didik yang berkaitan langsung dengan proses pembelajaran dan sangat menentukan keberhasilan mereka di sekolah. Kemampuan kognitif siswa dapat dilihat dari keaktifan siswa dan kemandirian siswa maupun kemampuan siswa dalam pembelajaran. Dengan bekal pemahaman tersebut, guru akan dapat memberikan layanan pendidikan atau melaksanakan proses pembelajaran yang sesuai dengan kemampuan kognitif peserta didik yang dihadapinya. (Desmita, 2010).

Anak-anak yang tidak dilatih mandiri sejak usia dini, akan menjadi individu yang tergantung sampai remaja bahkan sampai dewasa nanti. Bila kemampuan-kemampuan yang seharusnya sudah dikuasai anak pada usia tertentu dan anak belum mau melakukan, maka si anak bias dikategorikan sebagai anak yang tidak mandiri. Contoh yang paling nyata adalah anak usia SD yang makan masih harus disuapi, dimandikan ataumasih banyak dibantu dalam kegiatan yang seharusnya sudah dapatdilakukan sendiri. Faktor-faktor yang mempengaruhi ke-mandirian adalah gen, pola asuh, pendidikan di sekolah, dan kehidupan di masyarakat(Ali \& Asrori, 2010, dalam Purbasari \& Nawangsari,2016).

Dalam proses perkembangan yang dialami seseorang akan memperoleh sikap secara kumulatif yaitu sikap kemandirian, dimana dalam proses menuju kemandirian, individu belajar untuk menghadapi berbagai situasi dalam lingkungan sosialnya sampai ia mampu berpikir dan mengambil tindakan yang tepat dalam mengatasi setiap situasi. Aktivitas bersama membantu anak untuk menanamkan cara berfikir dan bersikap di masyarakat dan menjadikannya sebagai caranya sendiri. Orang dewasa (teman sebaya yang lebih tua) seharusnya membantu mengarahkan dan mengorganisasi proses pembelajaran anak sehingga anak mampu menguasai dan menginternalisasikan secara mandiri (Sa'diyah, 2017). Kemandirian belajar adalah kemampuan seseorang untuk mengolah secara efektif pengalaman belajarnya sendiri dengan berbagai cara sehingga mencapai hasil belajar yang optimal. Mengembangkan kemandirian siswa adalah suatu strategi yang penting agar siswa dapat menentukan sendiri pilihanpilihan kegiatan belajar, target dan cara mencapai target yang telah ditetapkan dalam belajar.

Belajar mandiri bukan merupakan usaha untuk mengasingkan siswa dari teman belajar dan guru. Siswa boleh bertanya, berdiskusi ataupun meminta penjelasan dariorang lain. Kemandirian belajar akan terbentuk dari proses belajar mandiri. Hal yang terpenting dalam proses belajar adalah peningkatan kemampuan dan keterampilan siswa dalam proses belajar tanpa bantuan orang lain, sehingga pada akhirnya siswa tidak tergantung pada guru, pembimbing, teman, atau orang lain dalam belajar. Kemandirian belajar ini juga dituntut dalam kurikulum fisika. Tuntutan pengembangan kemampuan kemandirian belajar yang tertulis dalam kurikulum fisika antara lain menyebutkan bahwa siswa bukan hanya sekedar menghafalkan rumus-rumus yang terdapat dalam materi pelajaran namun harus memehami konsep yang terkandung dalam rumus tersebut.

Kemandirian anak ditandai dengan adanya kemampuan untuk melakukan aktivitas sederhana sehari-hari, seperti makan tanpa harus disuapi, mampu memakai kaos kaki dan sepatunya sendiri, dan kegiatankegiatan lain tanpa tergantung dengan orang lain. Kemandirian akan dicapai oleh anak melalui proses belajar atau pendidikan (Nakita, 2005). Tingkat kemandirian di tingkat SMP terbilang masih rendah. Sebagai contoh, (1) siswa tidak melakukan persiapan sebelum menghadapi pembelajaran di sekolah, dan mempelajari materi pembelajaran hanya apabila akan dilaksanakan tes, (2) ketika mengerjakan suatu materi yang diterapkan pada persoalan nyata siswa cenderung sulit untuk mengerjakan walaupun sebenarnya sama dengan persoalan yang ada, (3) dan apabila diminta untuk maju ke depan mengerja kansuatu soal hanya menunggu teman yang lain untuk mengerjakannya di depan kelas. 
Sehubung dengan masih banyak siswa yang kurang baik dalam hal kemandirian belajar yang dilihat dari rutinitas sehariharinya, untuk itu penulis ingin membuat angket yang berguna untuk melihat tingkat kemandirian belajar siswa dari rutinitas seharihari, dan penulis juga akan mengujicobakan angket ini terhadap siswa SMP sebanyak 40 siswa dengan soal angketnya sebanyak 25 soal. Hal ini dilakukan untuk mengetahui apakah angket yang penulis berikan dapat dijadikan ukuran untuk melihat tingkat kemandirian belajar siswa SMP NOMENSEN di Kota Jambi.

\section{METODE PENELITIAN}

Jenis penelitian yang dipakai adalah penelitian deskriptif kuantitatif yaitu penelitian mendeskriptifkan atau menganalisi data-data secara kuantitatif dan diolah secara statistika, dengan tujuan untuk menguji hipotesis yang telah ditetapkan lalu menginterpretasikan hasil analisis tersebut untuk memperoleh kesimpulan (Sugiyono, 2014). Sedangkan, Menurut Arikunto (2013), penelitian deskriftif merupakan penelitan yang dimaksudkan untuk mengumpulkan informasi mengenai status suatu gejala yang ada, keadaan gejala menurut keadaan atau situasiyang sesungguhnya pada saat penelitian dilakukan. Penelitian ini dilakukan untuk menentukan tingkat kemandirian pada siswa SMP yang dilihat dari rutinitas atau kebiasaan sehari-hari.

Penelitian diperlukannya sebuah instrumen penelitian. Menurut Sugiyono (2009), instrumen penelitian merupakan suatu alat yang digunakan untuk mengukur fenomena alam maupun sosial. Instrumen penelitian adalah sesuatu yang berperan penting dalam pengambilan data, dari instrument penelitian juga dapat menetukan kualitas dari data yang diperoleh. Instrument data dapat berupa angket atau kuisioner. Kusioner atau angket merupakan teknik pengumpulan data yang dilakukan dengan cara memberi seperangkat atau pernytaan tertulis kepeda responden untuk dijawab (Sugiyono, 2010). Angket dalam penelitian ini merupakan angket kemandirian yang mempunyai 4 indikator dan 25 pertanyaan, yaitu sangat baik, baik, kurang baik dan tidak baik. Angket ini merupakan angket tertutup dimana yang dimaksud dengan angket tertutup adalah siswa menjawab sesuai dengan kemampuannya atau keinginannya sendiri.
Tempat dilakukanya penelitian adalah di Sekolah Menengah Pertama NOMENNSEN Kota Jambi. Responden yang akan diambil datanya adalah sebanyak 40 siswa, 20 siswa kelas VII.1 dan 20 siswa kelas VII.2.

\section{HASIL \& PEMBAHASAN}

Pada hasil penelitian yang telah dilakukan terhadap 40 siswa yaitu 20 siswa kelas VII.1 dan 20 siswa kelas VII.2, maka didapatkan data sebagai berikut ini:

1. Deskripsi data kelas VII.1

Tabel 1.1 Skor Kemandirian Belajar Kelas VII.1

\begin{tabular}{|c|c|}
\hline no sampel & skor \\
\hline 1 & 72 \\
\hline 2 & 62 \\
\hline 3 & 60 \\
\hline 4 & 78 \\
\hline 5 & 67 \\
\hline 6 & 85 \\
\hline 7 & 82 \\
\hline 8 & 63 \\
\hline 9 & 72 \\
\hline 10 & 54 \\
\hline 11 & 73 \\
\hline 12 & 65 \\
\hline 13 & 60 \\
\hline 14 & 82 \\
\hline 15 & 81 \\
\hline 16 & 58 \\
\hline 17 & 70 \\
\hline 18 & 74 \\
\hline 19 & 58 \\
\hline 20 & 67 \\
\hline
\end{tabular}

Melalui perhitunggan dengan menggunkan SPSS kita dapat memperoleh data dari tabel 1.1 yaitu skor minimum (terendah) 54, skor maksimum (tertinggi) 85, mean 69,15, median 68,5, modus 58 dan standar deviasi 9,2239. Untuk hasil perhitunggan dengan menggunakan SPSS dapat dilihat pada tabel 1.2. 
Tabel 1.2 Data SPSS

Statistics

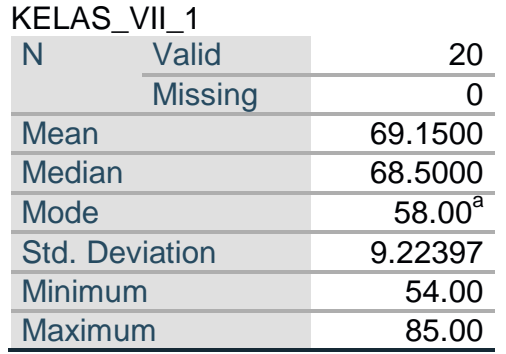

Setelah mengetahui data dari SPSS, langkah selanjutnya yaitu menentukan persenan dari 4 indikator pada angket untuk menentukan persentase banyaknya siswa pada masing-masing indikator. Sebelum itu diperlukannya perhitungan interval terhadap skor-skor yang telah diperoleh. Untuk menghitung interval dilakukan dengan cara manual menggunkan rumus seperti dibawah ini:

$$
R=\frac{(S T \times J P)-(S R \times J P)}{S T}
$$

Keterangan : $\mathrm{R}=$ Rentang

$$
\begin{aligned}
& \mathrm{ST}=\text { Skala Indikator Tertinggi } \\
& \mathrm{JP}=\text { Jumlah Pernyataan } \\
& \text { Angket } \\
& \mathrm{SR}=\text { Skala Indikator }
\end{aligned}
$$

Untuk menghitung persentase juga menggunakan cara manual dengan rumus:

$$
\%=\frac{f}{n} \times 100 \%
$$

\begin{tabular}{|c|c|c|c|c|}
\hline \multirow{2}{*}{ No } & \multirow{2}{*}{ Interval } & \multicolumn{2}{|c|}{ Frekuensi } & \multirow{2}{*}{ kategori } \\
\hline & & Frekuensi & $\%$ & \\
\hline 1 & $\begin{array}{c}25- \\
43,75\end{array}$ & 0 & $0 \%$ & $\begin{array}{l}\text { Tidak } \\
\text { Baik }\end{array}$ \\
\hline 2 & $\begin{array}{c}43,76- \\
62,5\end{array}$ & 6 & $30 \%$ & $\begin{array}{c}\text { Kurang } \\
\text { Baik }\end{array}$ \\
\hline 3 & $\begin{array}{c}62,51- \\
81,25\end{array}$ & 11 & $55 \%$ & Baik \\
\hline 4 & $\begin{array}{c}81,26- \\
100\end{array}$ & 3 & $15 \%$ & $\begin{array}{c}\text { Sangat } \\
\text { Baik }\end{array}$ \\
\hline
\end{tabular}

Keterangan $: \mathrm{f}=$ frekuensi

$$
\mathrm{n}=\text { total responden (siswa) }
$$

Dari rumus-rumus diatas didapatlah data seperti tabel 1.3 dibawah ini.

Tabel 1.3 Sebaran Frekuensi Skor Kemandirian Belajar Kelas VII.1

Tabel diatas menunjukkan bahwa di kelas VIII.1 tidak ada siswa yang memiliki kemandirian yang tidak baik dengan persentase $0 \%, 6$ orang siswa yang tingkat kemandirian kurang baik dengan persentase $30 \%, 11$ orang siswa yang memiliki tingkat kemandirian yang baik dengan persentase $55 \%$, dan hanya 3 orang siswa yang memiliki tingkat kemandirian sangat baik dengan persentase $15 \%$. Dalam angket yang diberikan terdapat pernyataan-pernyataan tentang rutinitas sehari-hari yang dapat menggambarkan tingkat kemandirian dari seorang siswa. Jadi, secara garis besar di kelas VII.1 siswa sudah memiliki karakter kemandirian dengan indikator baik-sangat baik dilihat dari persentasi penskoranya.

2. Deskripsi data kelas VII.2

Tabel 1.4 Skor Kemandirian Belajar Kelas

\begin{tabular}{|c|c|}
\hline $\begin{array}{c}\text { no } \\
\text { sampel }\end{array}$ & skor \\
\hline 1 & 65 \\
\hline 2 & 64 \\
\hline 3 & 70 \\
\hline 4 & 77 \\
\hline 5 & 65 \\
\hline 6 & 58 \\
\hline 7 & 73 \\
\hline 8 & 69 \\
\hline 9 & 62 \\
\hline 10 & 59 \\
\hline 11 & 78 \\
\hline 12 & 68 \\
\hline 13 & 74 \\
\hline 14 & 72 \\
\hline 15 & 64 \\
\hline 16 & 64 \\
\hline 17 & 64 \\
\hline 18 & 63 \\
\hline 19 & 81 \\
\hline 20 & 81 \\
\hline & \\
\hline
\end{tabular}

Melalui perhitunggan dengan menggunkan SPSS kita dapat memperoleh data dari tabel 1.4 yaitu skor minimum (terendah) 58, skor maksimum (tertinggi) 81, mean 68,55, median 66,5, modus 64 dan standar deviasi 6,95455. Untuk hasil perhitunggan dengan menggunakan SPSS dapat dilihat pada tabel 1.5. 
Tabel 1.5 Data SPSS Kelas VII.2

\begin{tabular}{|c|c|c|}
\hline \multicolumn{3}{|c|}{$\begin{array}{ll} & \text { Statistics } \\
\text { KELAS VII } 2\end{array}$} \\
\hline & VII_2 & \\
\hline \multirow[t]{2}{*}{$\mathrm{N}$} & Valid & 20 \\
\hline & Missing & 0 \\
\hline & & 68.5500 \\
\hline & & 66.5000 \\
\hline & & 64.00 \\
\hline & ation & 6.95455 \\
\hline & & 58.00 \\
\hline & & 81.00 \\
\hline
\end{tabular}

Sama dengan data kelas VII.1 setelah mengetahui data dari SPSS, langkah selanjutnya yaitu menentukan persenan dari 4 indikator pada angket untuk menentukan persentase banyaknya siswa pada masingmasing indikator. Sebelum itu diperlukannya perhitungan interval terhadap skor-skor yang telah diperoleh. Untuk menghitung interval dilakukan dengan cara manual menggunkan rumus yang sama seperti sebelumnya. Begitu juga untuk menghitung persentase. Sehingga didapatkanlah hasil seperti tabel 1.6 berikut.

Tabel 1.6 Sebaran Frekuensi Skor Kemandirian Belajar Kelas VII.2

\begin{tabular}{|c|c|c|c|c|}
\hline \multirow{2}{*}{ No } & \multirow{2}{*}{ Interval } & \multicolumn{2}{|c|}{ Frekuensi } & \multirow{2}{*}{ kategori } \\
\hline & & Frekuensi & $\%$ & \\
\hline 1 & $\begin{array}{c}25- \\
43,75 \\
\end{array}$ & 0 & $0 \%$ & $\begin{array}{l}\text { Tidak } \\
\text { Baik }\end{array}$ \\
\hline 2 & $\begin{array}{c}43,76- \\
62,5\end{array}$ & 3 & $15 \%$ & $\begin{array}{c}\text { Kurang } \\
\text { Baik }\end{array}$ \\
\hline 3 & $\begin{array}{c}62,51- \\
81,25\end{array}$ & 17 & $85 \%$ & Baik \\
\hline 4 & $\begin{array}{c}81,26- \\
100\end{array}$ & 0 & $0 \%$ & $\begin{array}{c}\text { Sangat } \\
\text { Baik }\end{array}$ \\
\hline
\end{tabular}

Tabel diatas menunjukkan bahwa di kelas VIII.2 tidak ada siswa yang memiliki kemandirian yang tidak baik dengan persentase $0 \%, 3$ orang siswa yang tingkat kemandirian kurang baik dengan persentase $15 \%, 17$ orang siswa yang memiliki tingkat kemandirian yang baik dengan persentase $85 \%$, dan tidak ada siswa yang memiliki tingkat kemandirian sangat baik dengan persentase $0 \%$. Dari persentase skor yang didpat oleh siswa kelas VII.2 sebagian besar sudah memiliki karakter kemandirian dengan indikator baik.

\section{KESIMPULAN \& SARAN}

\section{Kesimpulan}

Dari penelitian yang telah dilakukan dapat disimpulkan bahwa, melatih kemandirian itu penting apalagi saat anak masih usia dini. Selain itu metatih kemandirian melalui kebisaan atau rutinitas sehari-hari membuat pembentukan karakter dan kemampuan anak menjadi lebih baik dan lebih cepat. Dengan terbentuknya kemandirian didalam diri anak sejak dini akan membantu proses belajarnya dengan lingkungan sekitar tanpa sepeuhnya dibantu oleh orang lain.

\section{Saran}

Setelah melakukan penelitian, masih banyak ditemukan siswa yang tingkat kemandiriannya masih rendah, saran saya agar guru dapat memberikan kegiata-kegiatan diluar mata pelajaran yang dapat melatih kemandirian anak. Agar anak terbiasa dan melatih nya dalam dirinya sendiri.

\section{DAFTAR PUSTAKA}

Aini , Pratistya Nor \& Taman, Abdullah. 2012. Pengaruh kemandirian belajar dan lingkungan belajar siswa terhadap prestasi belajar akuntansi siswa kelas xi ips sma negeri 1 sewon bantul tahun ajaran 2010/2011. Jurnal Pendidikan Akuntansi Indonesia. No. 1, Vol. X.

Arikunto, S., 2013. Prosedur Penelitian, Suatu Pendekatan Praktik. Jakarta, Rineka Cipta.

Desmita, 2010, Psikologi Perkembangan Peserta Didik, Bandung, PT. Remaja Rosdakarya.

Nakita, 2005, Menjadikan Anak Mandiri, Nakita, Apri, Hal 13-19.

Pratiwi , Tika Resti \& Muslim. 201., Pembelajaran Ipa Tipe Integrated Untuk Meningkatkan Keterampilan Berpikir Kritis Siswa SMP. Jurnal Pendidikan Fisika Indonesia ,23553812.

Purbasari, Kamelia Dewi \& Nawangsari, Nur Ainy Fardana. 2016. Perbedaan Kemandirian pada Remaja yang Berstatus Sebagai Anak Tunggal Ditinjau dari Persepsi Pola Asuh Orangtua. Jurnal Psikologi Pendidikan dan Perkembangan .No. 1, Vol 5 .

Sa'diyah, Rika., 2017, Pentingnya Melatih Kemandirian Anak, No. 1, Vol. XVI.

Sugiyono., 2009, Metode Penelitian Pendidikan (Pendekatan kuantitatif, 
kualitatif dan R\&D), Bandung:

Alfabeta.

Sugiyono., 2010. Metode Penelitian

Pendidikan Pendekatan kuantitatif,

kualitatif dan R\&D. Bandung:

Alfabeta.

Sugiyono., 2014, Metode Penelitian Kualitatif, kuantitatif dan R\&D, Bandung, Alfabeta. 